\title{
RESPONSES OF BARLEY SEEDLINGS TO SALINITY AND DROUGHT UNDER FREEZE-THAW CONDITIONS
}

\author{
TANG, W. ${ }^{1}-$ BAO, G. ${ }^{1 *}-$ YAN, B. $^{2}-$ QU, Y. $.{ }^{1}-$ GUO, J. ${ }^{1}-$ ZHU, S. ${ }^{1}-$ ZHAO, H. ${ }^{3}$ \\ ${ }^{1}$ Key Laboratory of Groundwater Resources and Environment of the Ministry of Education, \\ Jilin Provincial Key Laboratory of Water Resources and Environment, College of New Energy \\ and Environment, Jilin University, Changchun 130012, China \\ ${ }^{2}$ Environmental Monitoring Center Station of Jilin Province, Changchun 130011, China \\ ${ }^{3}$ The Administration of Jingyu Water Conservation, Jingyu 135200, Jilin Province, China \\ ${ }^{*}$ Corresponding author \\ e-mail: baogz@jlu.edu.cn; fax: +86-0431-8850-2606
}

(Received 21 $1^{\text {st }}$ Dec 2020; accepted $3^{\text {rd }}$ Mar 2021)

\begin{abstract}
The Qinghai-Tibet Plateau is known for its high altitude, low rainfall and varying temperature, and the crops in this area are susceptible to abiotic stresses induced by drought, salinity and freeze-thaw conditions that cause damages to different properties such as the permeability of biological membrane, osmotic adjustment, and antioxidant enzyme system. Barley (Hordeum vulgare L.) is an indispensable crop on the plateau and plays an important role in agricultural ecosystem as well. In this study, Beiqing 3 was used as experimental material and physiological characteristics, including soluble protein (SP) content, malondialdehyde (MDA) content, antioxidant enzyme activity and relative water content (RWC) of seedlings were examined under freeze-thaw conditions combined with drought and alkali stress. Research results indicated that under the combined stresses of salinity and drought, barley seedlings were damaged by lipid peroxidation, weakened superoxide dismutase (SOD), catalase (CAT) and peroxidase (POD) activities, while osmotic adjustment ability in plants cell was enhanced. We suggested that, in agricultural management, the simultaneous occurrence of two stresses, salinity and drought, should be avoided in the early stage of barley planting to reduce the physiological stress on plants.

Keywords: abiotic stresses, antioxidant enzyme activity, soluble protein, physiological effects, malondialdehyde
\end{abstract}

\section{Introduction}

Lying in the Southern Qinghai-Tibet Plateau, the Brahmaputra Valley, where altitude varies from $2600 \mathrm{~m}$ to $3500 \mathrm{~m}$, was known for the complex and changeable terrain, forming a unique plateau climate characteristic (Zhang et al., 2019). The fact that, during early spring, the freeze-thaw often occurs due to the long sunshine hours and the changeable temperature between day and night has various effects on the external morphology and internal physiological metabolism of plants (Arfan et al., 2019; Wang et al., 2019; Xu et al., 2019). It has been reported that the average precipitation of barley planting region is less than $400 \mathrm{~mm}$, besides, $90 \%$ of the annual precipitation occurs in June to September, which tends to cause spring drought and affect spring sowing and early crop growth (Hou et al., 2018). The seasonal uneven precipitation and the exceeding evaporation on the Brahmaputra Valley make drought stress prone to occur during crop growth (Bibi et al., 2019), which often causes oxidative stress by the accumulation of reactive oxygen species in plants (Souza et al., 2004), affecting the structure and growth of plant (Duan et al., 2007). Attributing to current climate, the content of sodium bicarbonate $\left(\mathrm{NaHCO}_{3}\right)$ and sodium chloride $(\mathrm{NaCl})$ in soil has increased on the 
Brahmaputra Valley, where salinization becomes increasingly serious. It has been confirmed that alkali stress imposed more harm to crops than salt stress does (AlvarezAcosta et al., 2019). Besides, one paper has previously reported that high $\mathrm{pH}$ of alkali stress can short root length and seedlings height of rye, reduce the content of water and chlorophyll and decrease the relative transpiration rate (Guo et al., 2012).

Barley, a cereal crop of the genus Gramineae, can grow at an altitude of $3000 \sim 3400 \mathrm{~m}$. Among them, Beiqing 3 has good resistance to cold and drought (Ahmed et al., 2015; He et al., 2015), is the main crop in Tibet and Qinghai. In this experiment, as materials, the Beiqing 3 seedlings were treated with salinity, drought and freeze-thaw stress to artificially simulate the growing environment of plants. The relative water content (RWC), antioxidant enzyme activity, contents of malondialdehyde (MDA) and soluble protein (SP) were examined in order to study the response characteristics of plants to drought, salinity and freeze-thaw.

\section{Materials and methods}

\section{Seeds cultivation and salinity treatment}

The study was taken out in Northeast China. The full-grained seeds were selected and soaked with $0.1 \% \mathrm{KMnO}_{4}$ solution for $2 \mathrm{~h}$ for disinfection, after which the seeds were rinsed with deionized water until the water becoming clear, then we spread 120 seeds evenly on each of 8 culture dishes randomly named FSD, FS, FD, F, SD, S, D and C (Table 1). 1/2 of Hoagland nutrient solution was used to prepare $60 \mathrm{~m} M \mathrm{NaHCO}_{3}$ mixed solution ( $\mathrm{pH}=8.06), 500 \mathrm{ml}$ of which was added to the cultivated dishes of FSD, FS, SD and $\mathrm{S}$ at the same time, $500 \mathrm{ml} \mathrm{1/2}$ Hoagland nutrient solution was added to the others (FD, F, D and C). 8 dishes of seeds were placed in MGC-450BP light incubator (Shanghai Yiheng Scientific Instruments Co., Ltd) for germination (Fig. la), of which the cultivated conditions were set as $12 \mathrm{~h}$ light $\left(25^{\circ} \mathrm{C}\right)$ and $12 \mathrm{~h}$ non-light $\left(15^{\circ} \mathrm{C}\right)$. Daily watering $(50 \mathrm{ml})$ was necessary during the cultivation.

Table 1. Experimental design of groups under salinity (S), drought (D) and freeze-thaw $(F)$ stress

\begin{tabular}{c|c|c|c|c|c|c|c|c}
\hline & FSD & FS & FD & F & SD & S & D & C \\
\hline Salinity & + & + & - & - & + & + & - & - \\
Drought & + & - & + & - & + & - & + & - \\
Freeze-thaw & + & + & + & + & - & - & - & - \\
\hline
\end{tabular}

+ add stress, - no stress

\section{Drought treatment}

After seedlings were cultivated to $15 \mathrm{~cm}$ high with 2 or 3 leaves (around 1 week), they were treated with drought stress. $\mathrm{NaHCO}_{3}$ mixed solution was used to prepare $20 \%$ PEG-6000 mixed solution for combined treatment of salinity and drought stress, and 1/2 Hoagland nutrient solution was used to prepare 20\% PEG-6000 solution. The solution in the cultivated dishes of Group FSD and Group SD was replaced with $500 \mathrm{ml}$ PEG-NaHCO 3 mixed solution, in the cultivated dishes of Group FD and Group D replaced with $500 \mathrm{ml}$ PEG solution, in the cultivated dishes of Group FS and Group S 
replaced with $500 \mathrm{ml} \mathrm{NaHCO}_{3}$ solution, in the cultivated dishes of Group F and Group C replaced with $500 \mathrm{ml} \mathrm{1/2} \mathrm{Hoagland} \mathrm{nutrient} \mathrm{solution.} \mathrm{The} \mathrm{drought} \mathrm{treatment} \mathrm{lasted} \mathrm{for}$ $48 \mathrm{~h}$ without watering.

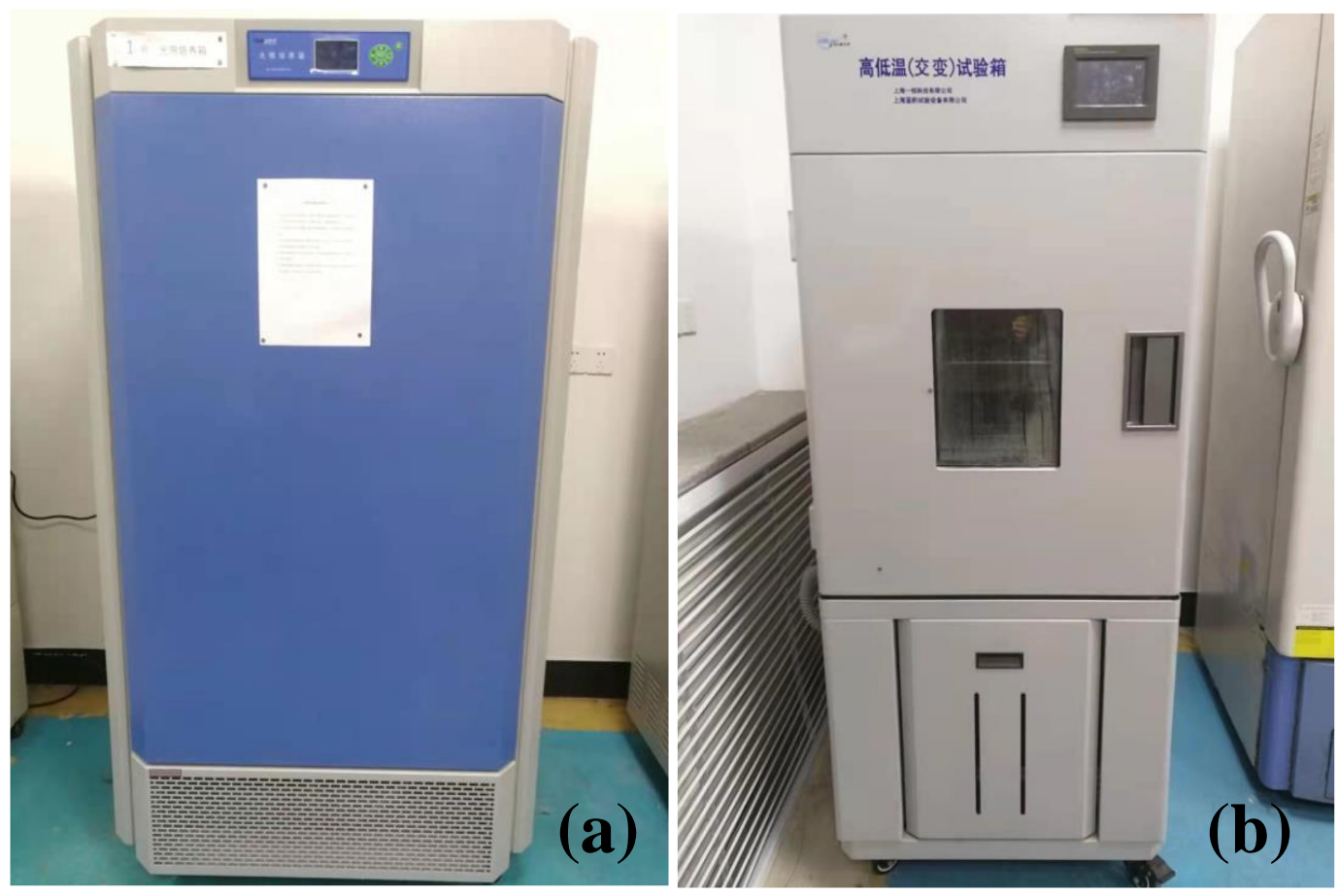

Figure 1. Photos of experimental equipment. (a): $M G C-450 B P$ light incubator (Shanghai Yiheng Scientific Instruments Co., Ltd). (b): BPHJ-120A high-low-temperature test chamber (Shanghai Yiheng Scientific Instruments Co., Ltd)

\section{Freezing and thawing stress treatment and sampling}

After drought treatment, the cultivated dishes of Groups FSD, FS, FD and F were put into BPHJ-120A high-low-temperature test chamber (Shanghai Yiheng Scientific Instruments Co., Ltd) to carry out a freeze-thaw cycle for a period of $14 \mathrm{~h}($ Fig. 1 b), with the temperature curve being set as $15,10,5,0,-5,0,5$ and $10^{\circ} \mathrm{C}$, while other cultivated dishes of Groups SD, S, D and C were maintained in light incubator under previous culture conditions (Fig. 2a). Initially, the cultivated dishes were placed in the chamber at $15{ }^{\circ} \mathrm{C}$ that closed to room temperature at night. Controlled precisely by program, the temperature decreased to $-5{ }^{\circ} \mathrm{C}$ steadily at a speed around $0.04{ }^{\circ} \mathrm{C} / \mathrm{min}$, and then the temperature increased from -5 to $10{ }^{\circ} \mathrm{C}$ at a speed around $0.04{ }^{\circ} \mathrm{C} / \mathrm{min}$. After the freezethaw cycle being started, five parallel samples were taken every 2 hours from 8 cultivated dishes at random according to the required amount of the measurement, the corresponding sampling temperature was $10,5,0,-5,0,5,10^{\circ} \mathrm{C}$ respectively (Gong et al., 2020). All the samples were firstly wrapped up with tin foil paper, secondly fixed in liquid nitrogen immediately for $50 \mathrm{~s}$ and finally put into the ultra-low-temperature freezer at $-80{ }^{\circ} \mathrm{C}$ for storage in order to measure the content of MDA and soluble protein, SOD, POD and CAT activity. At the same time, fresh leaves were taken to determinate RWC. 


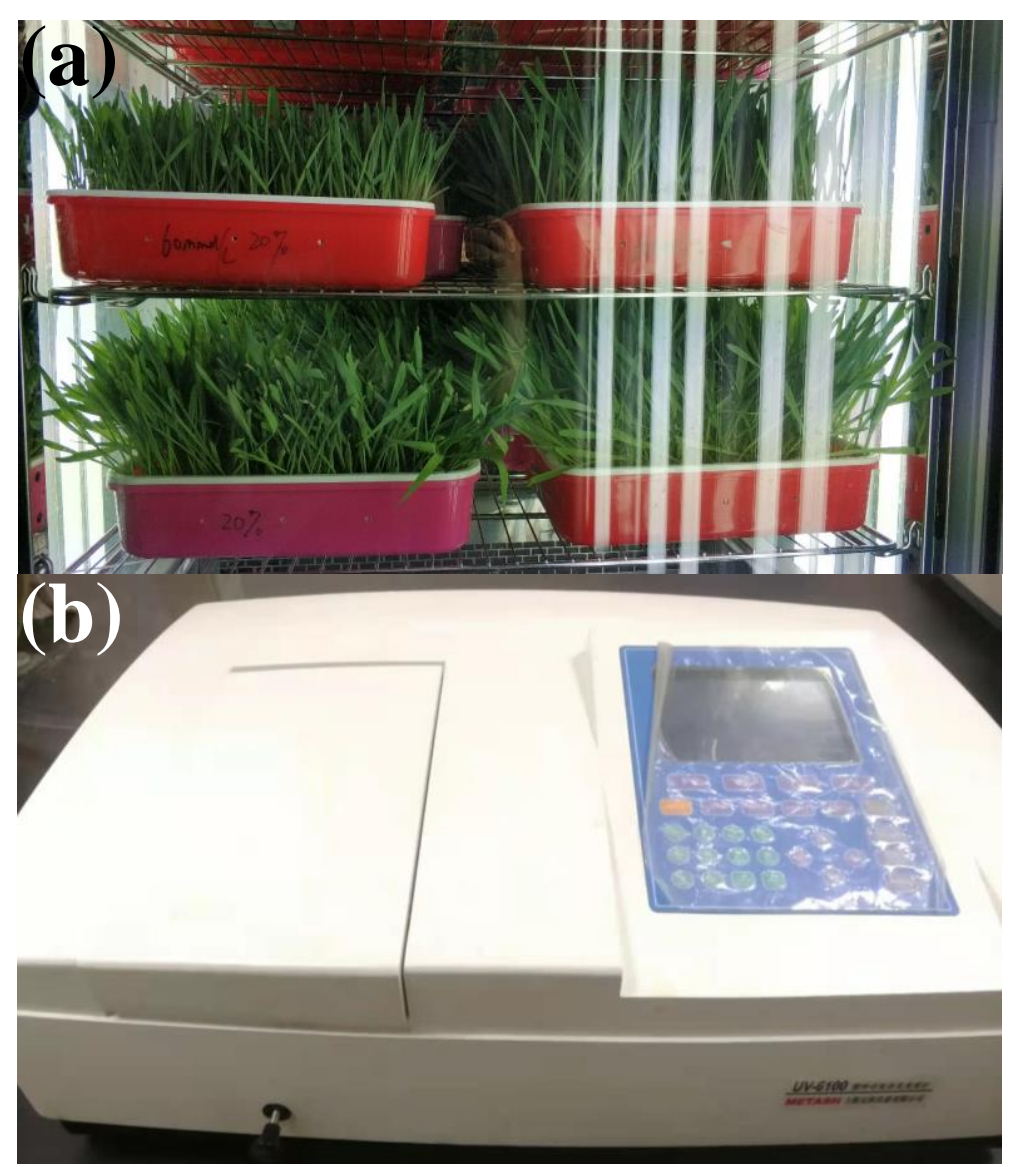

Figure 2. Photos of experimental culture and equipment. (a): 9-day barley seedlings in light incubator. (b): UV-6100 UV-visible spectrophotometer (Metash Co. Ltd)

\section{Analysis}

\section{Relative water content ( $R W C)$}

The relative water content of seedlings was determined by the oven drying method (Colom and Vazzana, 2001). For each sample (around $0.1 \mathrm{~g}$ ), fresh weight supposed to be measured and recorded as $\mathrm{F}_{\mathrm{W}}$ after drying the surface of leaves with filter paper. Completely being immersed in distilled water until the weight of leaves being constant, the leaves were taken out and wiped up with filter paper. The saturated fresh weight of the leaves at this time was measured and recorded as the Tw. Finally, the leaves were de-enzymed for $15 \mathrm{~min}$ in oven that was heated up to $105^{\circ} \mathrm{C}$, and then dried to a constant weight in $80^{\circ} \mathrm{C}$. The dry weight was measured and recorded as $\mathrm{D}_{\mathrm{W}}$. The RWC of leaves is calculated by formula Eq.1:

$$
\mathrm{RWC}=\left(\mathrm{T}_{\mathrm{w}}-\mathrm{D}_{\mathrm{W}}\right) /\left(\mathrm{F}_{\mathrm{W}}-\mathrm{D}_{\mathrm{W}}\right) \times 100 \%
$$

\section{Soluble protein $(S P)$ content}

The soluble protein content in seedlings was determined by the Coomassie brilliant blue method (Kong and Yi, 2008). $0.1 \mathrm{~g}$ leaves were selected randomly and shredded into a mortar, and then ground until homogenized with $5 \mathrm{ml}$ distilled water, which next was 
centrifuged with a TDL-40B centrifuge (Anting Scientific Instrument Factory, Shanghai) at a speed of $3000 \mathrm{r} / \mathrm{min}$ for $10 \mathrm{~min} .1 \mathrm{ml}$ of the supernatant was diluted in 5 times with $4 \mathrm{ml}$ distilled water, of which $1 \mathrm{ml}$ diluted supernatant was taken into a test tube with $5 \mathrm{ml}$ of Coomassie brilliant blue solution being added. After the mixed solution being shaken and placed for $2 \mathrm{~min}$, the absorbance of the solution was measured at $595 \mathrm{~nm}$ with a UV-6100 UV-visible spectrophotometer (Metash Co. Ltd) (Fig. 2b). The soluble protein content was calculated by standard curves.

\section{Malondialdehyde (MDA) content}

Malondialdehyde (MDA) content in seedlings was determined by the thiobarbituric acid method (Kong and Yi, 2008). $0.5 \mathrm{~g}$ leaves were selected randomly and shredded into a mortar, and then ground into a homogenate with $5 \mathrm{ml} 10 \%$ trichloroacetic acid (TCA) solution, which next was centrifuged at a speed of $4000 \mathrm{r} / \mathrm{min}$ for $10 \mathrm{~min}$. Then $2 \mathrm{ml}$ of the supernatant into was taken and fixed with $2 \mathrm{ml} 0.6 \%$ thiobarbituric acid (TBA) solution. Mixtures was bathed in $99{ }^{\circ} \mathrm{C}$ water for $15 \mathrm{~min}$, then cooled quickly in $5 \mathrm{~min}$ and centrifuged again at a speed of $4000 \mathrm{r} / \mathrm{min}$ for $10 \mathrm{~min}$ with a TDL-40B centrifuge (Anting Scientific Instrument Factory, Shanghai). The absorbance of supernatant was measured at $532 \mathrm{~nm}, 600 \mathrm{~nm}$, and $450 \mathrm{~nm}$ with a UV-6100 UV-visible spectrophotometer (Metash Co. Ltd). The MDA concentration and MDA content were calculated according to formulas Eq.2 and Eq.3.

$$
\begin{gathered}
\text { MDA concentration }(\mu \mathrm{mol} / \mathrm{L})=6.45 \times(\mathrm{D} 532-\mathrm{D} 600)-0.56 \times \mathrm{D} 450 \\
M D A \text { content }(\mu \mathrm{mol} / \mathrm{g})=\mathrm{cMDA} \times \mathrm{V}_{\mathrm{T}} / \mathrm{F}_{\mathrm{W}}
\end{gathered}
$$

where:

- D450, D532, D600 are the absorbance at 450nm, 532nm and 600nm, respectively.

- cMDA is MDA concentration ( $\mu \mathrm{mol} / \mathrm{L})$;

- $\mathrm{V}_{\mathrm{T}}$ is the volume of TCA solution (ml);

- $\mathrm{F}_{\mathrm{W}}$ is the fresh weight of seedlings $(\mathrm{g})$.

\section{Catalase (CAT), superoxide dismutase (SOD) and peroxidase (POD) activities}

The activities of CAT, SOD and POD were determined with the CAT, SOD and POD kits provided by Nanjing Jiancheng Biological Institute (Bao et al., 2017). A parallel sample (around $0.25 \mathrm{~g}$ ) were randomly taken and ground to a homogenate with $5 \mathrm{ml}$ phosphate buffer on ice. After centrifugations at a speed of $2500 \mathrm{r} / \mathrm{min}, 3500 \mathrm{r} / \mathrm{min}$ and $3500 \mathrm{r} / \mathrm{min}$ with a TDL-40B centrifuge (Anting Scientific Instrument Factory, Shanghai), respectively for $10 \mathrm{~min}$, the supernatant was used for following measurements according to instructions of kits.

\section{Data processing}

The experiments were repeated five times, and the data were expressed as mean \pm standard error (SE) ( $\mathrm{n}=5)$, which statistically performed with $\mathrm{R} 3.3 .1$ statistical software (R Foundation for Statistical Computing, Vienna, Austria) for one-way analysis of variance (ANOVA). When the variables were uniform, the significance analysis of data was analyzed using Duncan model, otherwise using Games-Howell model (Warner 2007). Pearson correlation coefficient was used to describe the correlation between 
variables. All results were shown in bars in figures plotted by Origin 8.0 software. Different letters presented in figures indicated significant differences between different treatment groups at the same time.

\section{Results}

\section{Effect on relative water content of seedlings}

In this experiment, the relative water content (RWC) in of 8 treatment groups decreased during freeze-thaw cycle. As shown from figure Fig. 3, RWC in barley seedlings had a maximum decrease under combined stresses of salinity and drought. The RWC in seedlings of Groups FS, FD and F had no significant differences compared to that in Groups S, D and C, respectively. However, in thawing stage, RWC in seedlings of Group FSD showed significant differences compared with that of Group SD. Notably, the RWC in barley seedlings of 4 freeze-thaw groups showed a sequence as F > FS > FD > FSD. Consistently, a similar order of RWC in seedlings can be observed among 4 non-freeze-thaw groups as well, that is, $\mathrm{C}>\mathrm{S}>\mathrm{D}>\mathrm{SD}$.

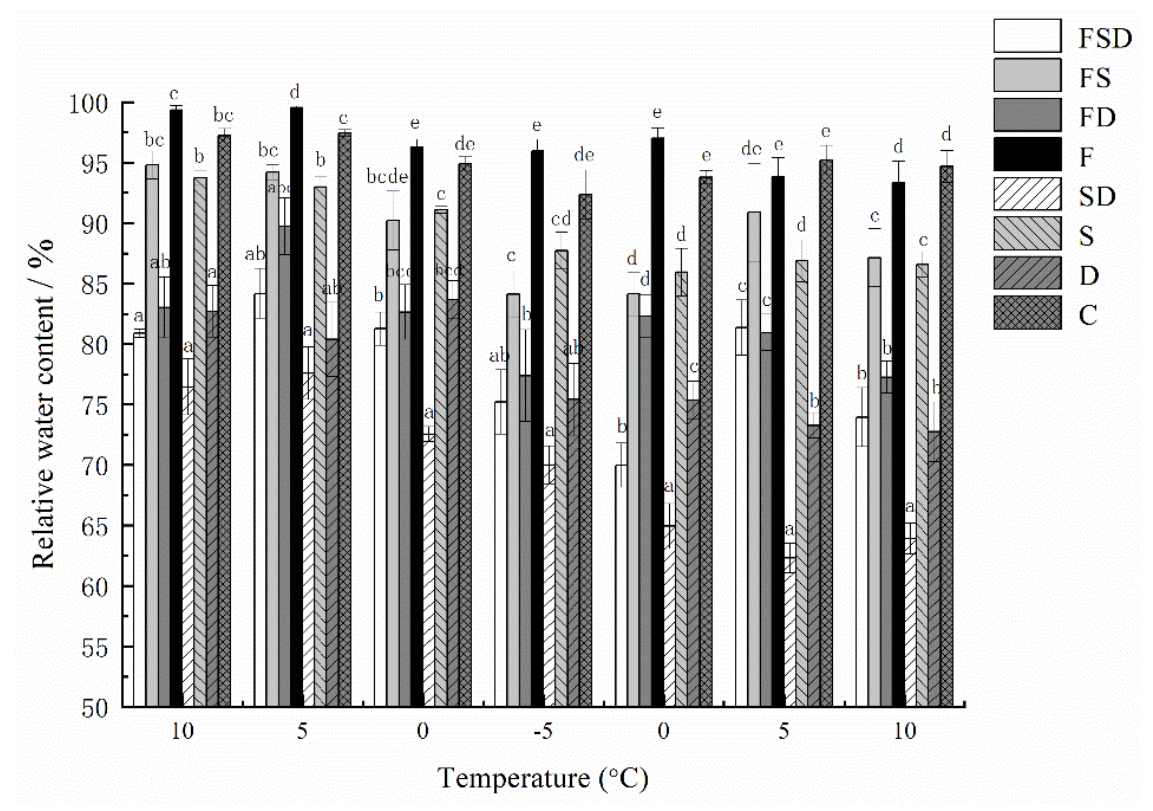

Figure 3. The relative water content in barley seedlings under different treatment. The letter $F$, $S, D$ and $C$ represent freeze-thaw stress, salinity stress, drought stress and control, respectively.

The temperature 10, 5, 0, -5, 0, 5 and $10^{\circ} \mathrm{C}$ means the corresponding sampling temperature. The different low-case letters mean the significant difference at the same temperature $(P<0.05)$

\section{Effect on soluble protein content of seedlings}

It can be observed that the soluble protein (SP) content in barley seedlings of 4 treatment groups under freeze-thaw stress (FSD, FS, FD and F) was higher than that of 4 treatment groups without freeze-thaw stress (SD, S, D and C), respectively (Fig. 4). The SP content in seedlings of Group SD and Group S was significantly higher than that of Group D and Group C $(P<0.05)$, which indicated that under non-freeze-thaw conditions, the SP content in seedlings increased due to the occurrence of salinity stress. 
Nevertheless, the SP content in seedlings of groups under either single freeze-thaw stress or single drought stress had no significant difference compared with that of control group $(P>0.05)$. In the case of freeze-thaw stress, the SP content in seedlings of Groups FSD, FS, FD and F increased during the period of freeze-thaw stage. Among them, Group FSD reached the maximum at $0^{\circ} \mathrm{C}$ (thawing stage), which exhibited a further $41.2 \%$ increase than the minimum $0^{\circ} \mathrm{C}$ (freezing stage). Somewhat differently, the other 3 groups (FS, FD and $\mathrm{F}$ ) all reached the maximum value at $5^{\circ} \mathrm{C}$ (thawing stage), and were $46.4 \%, 86.6 \%$ and $72.7 \%$ higher than the minimum value, respectively.

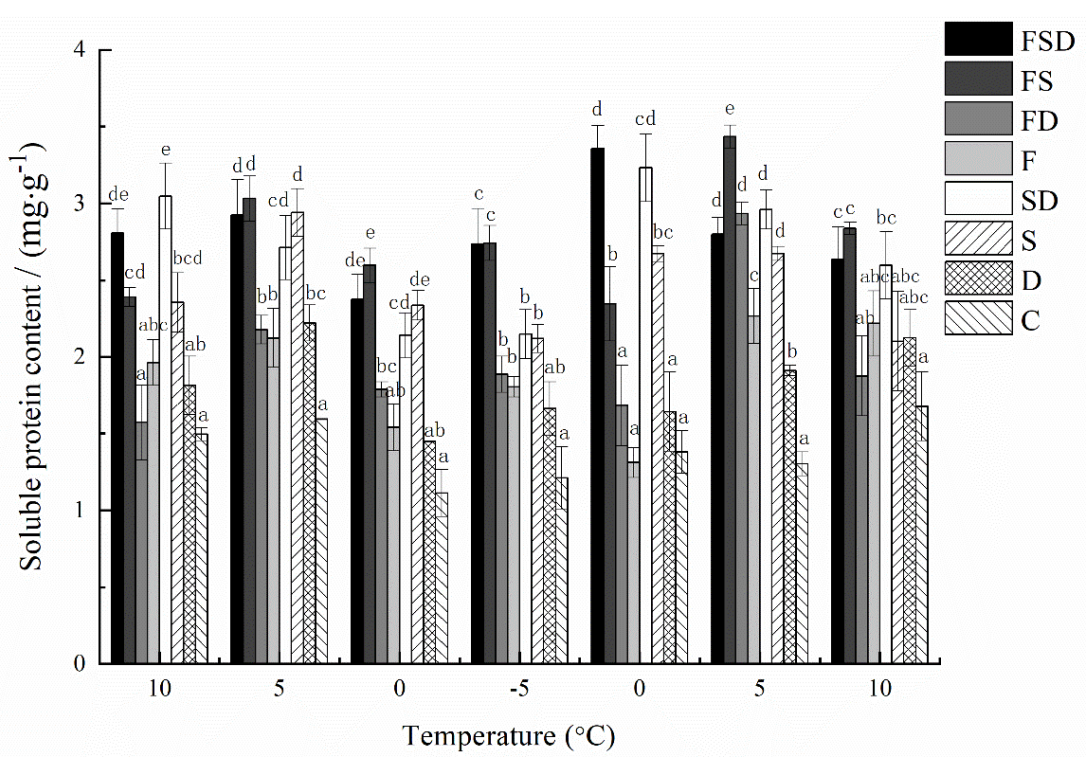

Figure 4. The soluble protein content in barley seedlings under different treatment. The letter $F$, $S, D$ and $C$ represent freeze-thaw stress, salinity stress, drought stress and control, respectively.

The temperature $10,5,0,-5,0,5$ and $10^{\circ} \mathrm{C}$ means the corresponding sampling temperature. The different low-case letters mean the significant difference at the same temperature $(P<0.05)$

\section{Effect on MDA content of seedlings}

Figure 5 shows that the malondialdehyde (MDA) content in barley seedlings of all experimental groups was higher than that of the control group. The non-freeze-thaw groups (SD, S, D and C) fluctuated little during a 14-hour freeze-thaw period, however the MDA content in barley seedlings of Group SD and Group S was significantly higher than that of Group D and C $(P<0.05)$. Besides, we have noticed that MDA content in barley seedlings in response to Group D was significantly higher than that in response to blank treatment $(P<0.05)$. Under the freeze-thaw stress, the MDA content in barley seedlings of single freeze-thaw group (F) was significantly lower than that of Groups FSD and FD $(P<0.05)$.

\section{Effect on SOD activity}

The SOD activity in barley seedlings of Groups FSD and SD had no significant difference compared with control group (C) (Fig. 6). The SOD activity significantly enhanced owing to the occurrence of drought stress in barley seedlings $(P<0.05)$, while significantly weakened due to the salinity stress in seedlings $(P<0.05)$. Under freeze- 
thaw stress, the SOD activity in barley seedlings of Groups FSD, FS, FD and F decreased at first and then increased. During the freeze-thaw cycle, except for $5^{\circ} \mathrm{C}$, the SOD activity in barley seedlings of Group FD was significantly higher than that of Groups FSD, FS and $\mathrm{F}(P<0.05)$.

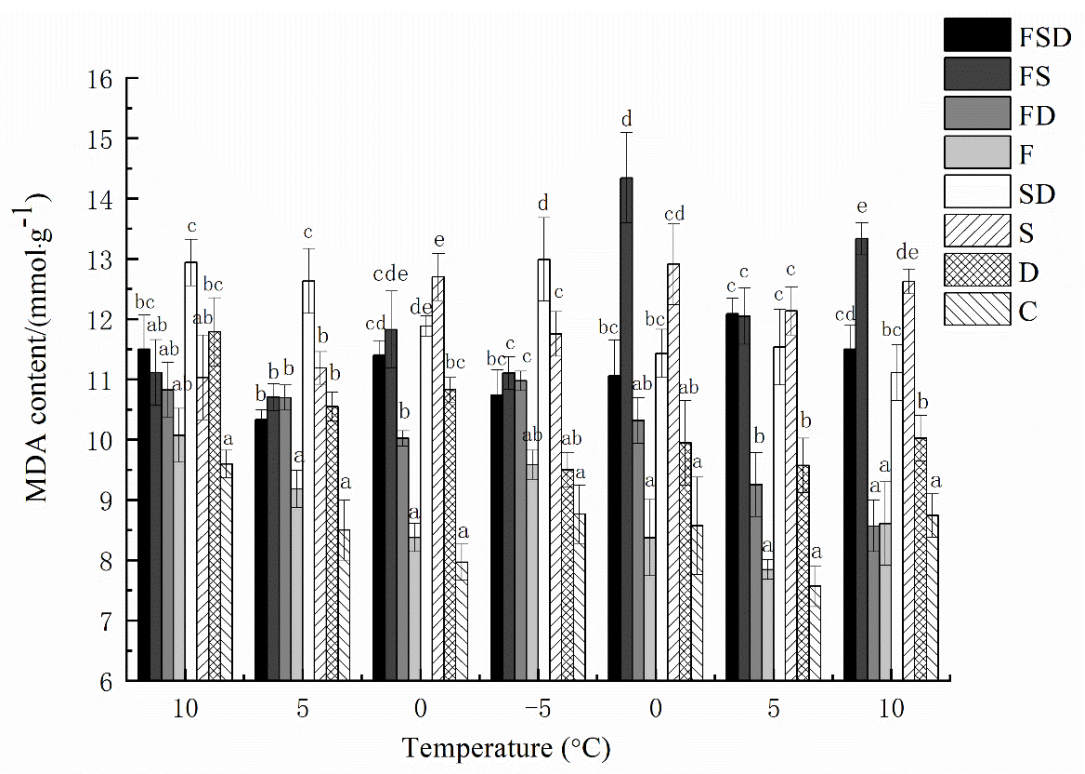

Figure 5. The malondialdehyde (MDA) content in barley seedlings under different treatment. The letter F, S, D and C represent freeze-thaw stress, salinity stress, drought stress and control, respectively. The temperature 10, 5, 0, -5, 0, 5 and $10^{\circ} \mathrm{C}$ means the corresponding sampling temperature. The different low-case letters mean the significant difference at the same temperature $(P<0.05)$

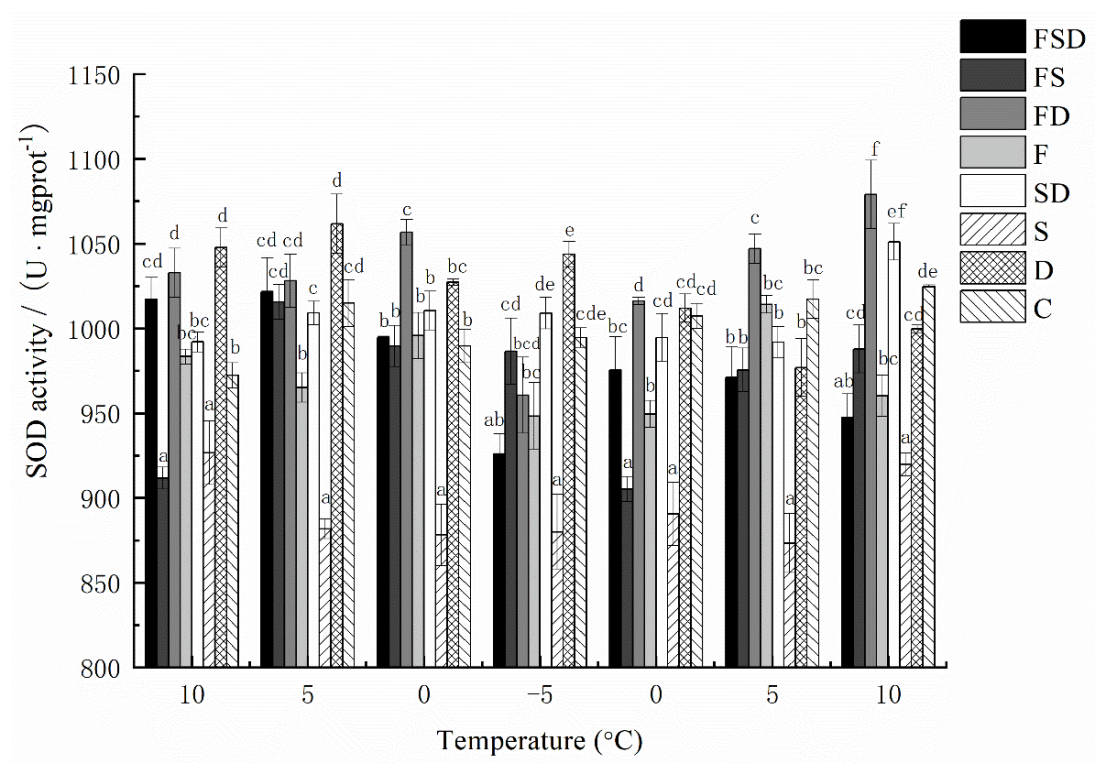

Figure 6. The SOD activity of barley seedlings under different treatment. The letter $F, S, D$ and $C$ represent freeze-thaw stress, salinity stress, drought stress and control, respectively. The temperature 10, 5, 0, -5, 0, 5 and $10^{\circ} \mathrm{C}$ means the corresponding sampling temperature. The different low-case letters mean the significant difference at the same temperature $(P<0.05)$ 


\section{Effect on CAT activity}

It can be seen from Figure 7 that, under non-freeze-thaw conditions, the CAT activity in barley seedlings of Groups SD, S and D was significantly lower than that of the control group $(P<0.05)$. CAT activity in seedlings of either Group F or Group FS showed a trend of initially increasing and then decreasing, while that of Group FD showing a general downward trend, and that of Group FSD showing an upward trend. Take if further, the CAT activity in seedlings of Group FSD was significantly lower than that of Group $\mathrm{F}$ $(P<0.05)$, and that of the Groups FS and FD was significantly lower than that of Group F only in the latter thawing case $(P<0.05)$.

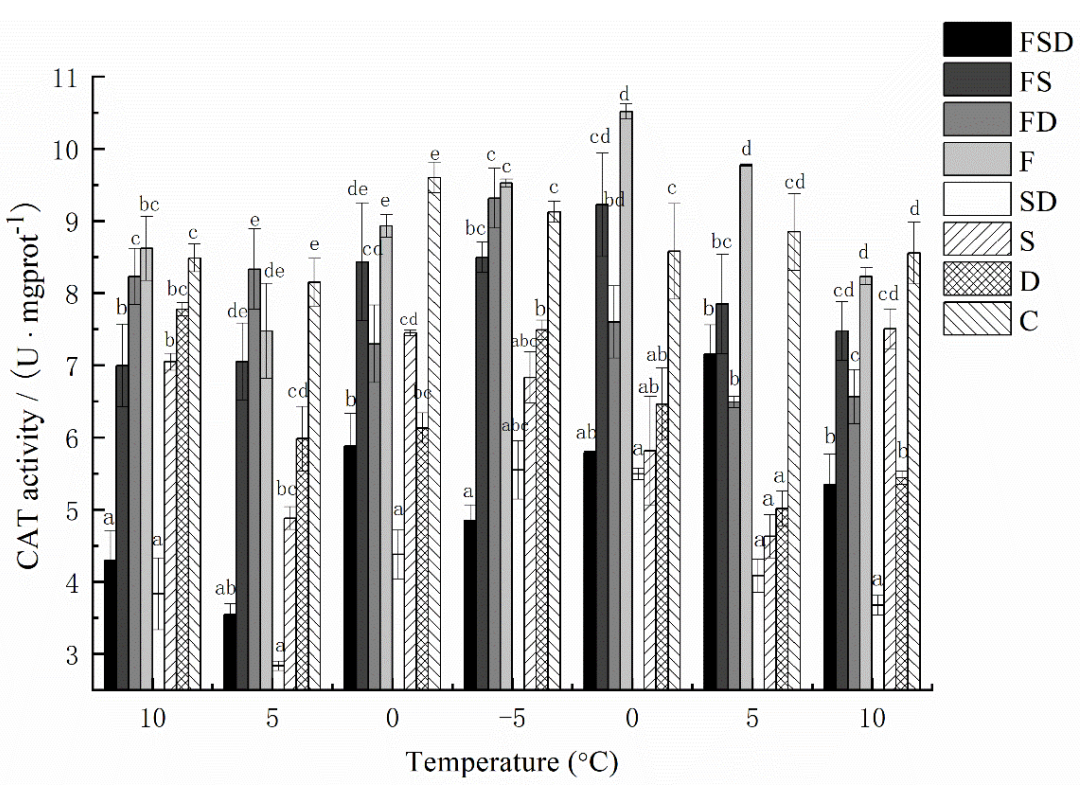

Figure 7. The CAT activity in barley seedlings under different treatment. The letter $F, S, D$ and $C$ represent freeze-thaw stress, salinity stress, drought stress and control, respectively. The temperature 10, 5, 0, -5, 0, 5 and $10^{\circ} \mathrm{C}$ means the corresponding sampling temperature. The different low-case letters mean the significant difference at the same temperature $(P<0.05)$

\section{Effect on POD activity}

In this experiment, during freeze-thaw cycle, the POD activity in barley of Groups FD and $\mathrm{F}$ showed a trend of initially increasing and then decreasing, while that of Groups FSD and FS showing an increasing trend (Fig. 8). When the temperature dropped to $10^{\circ} \mathrm{C}$ (freezing stage), the POD activity in barley seedlings of Groups F, S and D were significantly lower than that of control group $(P<0.05)$. Under salinity stress, the POD activity in seedlings significantly decreased within a freeze-thaw cycle $(P<0.05)$. Nevertheless, no significant difference was observed in POD activity between Groups FD and D. Accordingly, under freeze-thaw stress, there was a significant reducing of POD activity of groups subjected to salinity treatment, but no effect on that of groups subjected to drought treatment.

\section{Correlation analysis}

It can be observed from Table 2 that the content of SP and MDA in seedlings were significantly positively correlated under freeze-thaw conditions $(P<0.01)$. There was a 
significant negative correlation between SP content and antioxidant enzyme activity $(P<0.01)$. MDA was significantly negatively correlated with antioxidant enzyme activity and RWC, while CAT and POD were positively correlated $(P<0.01)$.

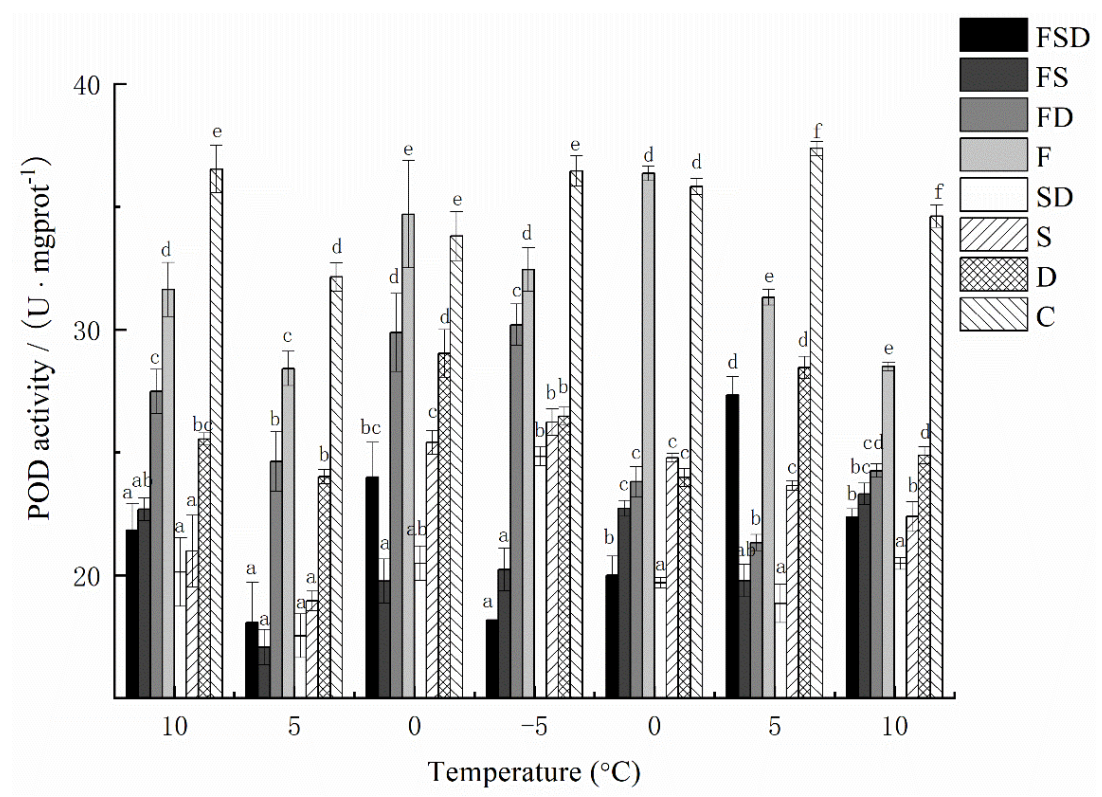

Figure 8. The POD activity in barley seedlings under different treatment. The letter F, S, D and $C$ represent freeze-thaw stress, salinity stress, drought stress and control, respectively. The temperature 10, 5, 0, -5, 0, 5 and $10^{\circ} \mathrm{C}$ means the corresponding sampling temperature. The different low-case letters mean the significant difference at the same temperature $(P<0.05)$

Table 2. Pearson correlation analysis between relative water content $(R W C)$, soluble protein $(S P)$ content, malondialdehyde (MDA) content, SOD, CAT and SOD activity in barley seedlings of freeze-thaw treatment groups

\begin{tabular}{c|cccccc}
\hline & RWC & SP & MDA & SOD & CAT & POD \\
\hline RWC & 1 & $-0.524^{* *}$ & $-0.427^{*}$ & -0.341 & $0.726^{* *}$ & $0.640^{* *}$ \\
SP & & 1 & $0.750^{* *}$ & -0.351 & $-0.799^{* *}$ & $-0.868^{* *}$ \\
MDA & & & 1 & $-0.407^{*}$ & $-0.663^{* *}$ & $-0.798^{* *}$ \\
SOD & & & & 1 & 0.052 & 0.213 \\
CAT & & & & & 1 & $0.833^{* *}$ \\
POD & & & & & & 1 \\
\hline
\end{tabular}

* Significant correlation at 0.05 level (both sides). ** Significant correlation at the 0.01 level (both sides)

\section{Discussion}

Either drought or alkaline salt can lead to a large amount of water loss in seedlings by reducing the osmotic pressure of plant cells (Shereen et al., 2019). It is one important conclusion from Alexander's research that the RWC of leaves is positively related to plant's stress resistance (Alexander et al., 2019). It has been reported that under the combined effects of water loss and high temperature, the reduction of RWC in Australian durum is greater than that under single stress (Liu et al., 2019). Consistently, in this 
experiment, the combined effects on RWC in barley seedling of salinity and drought were severer than the additive of salinity and drought alone; thus, interactions between the two stress factors were synergistic for RWC. Under freeze-thaw conditions, a decrease in temperature can not only ice the water in plant cells, but also caused a dehydration, resulting in a decrease in RWC (Iseri et al., 2013). As have shown that at the freezing stage, the decreased RWC contributed to alleviate the damage caused at freezing stage to plants and maintain the osmotic balance of plant cells (Hao et al., 2009).

Most of the soluble proteins in plants are enzymes involved in metabolism (Bao et al., 2019). An increase of soluble proteins can maintain the cell's higher osmotic potential, enhance the capacity of water absorption and holding, maintaining plant growth and improving resistance to stress (Yin et al., 2004). Here we observed from experiments that the SP content of barley seedlings increased under either drought or freeze-thaw stress (Groups F and D), while a higher accumulation of SP was measured in the groups subjected to basic-salt stress (FSD, FS, SD and S). These observations may attribute to the expression of resistant proteins in plant cells stimulated by alkaline stress, increasing the content of SP participating in osmotic adjustment in cells, thus making plants adapt to the external environment (Hazman et al., 2016). Under freeze-thaw stress, the SP content in seedlings of groups subjected to freeze-thaw stress decreased with the dropping temperature, which may be due to the accelerated decomposition of soluble proteins in cells, providing plants with energy to relieve the damage caused by stresses (Bae et al., 2006). At thawing stage, with the temperature rising to $10^{\circ} \mathrm{C}$, the SP content in seedlings increased. These findings are similar to the results of Lee's research, in which they examined the proteomic changes of rice roots under low temperature stress and found that the expressions of 27 proteins were up-regulated at $10^{\circ} \mathrm{C}$ (Lee et al., 2009).

The activity changes of antioxidant enzyme in plants caused by abiotic environmental stresses may have an effect on physiological characteristics to reduce damage (Ahsan et al., 2007). In a previous study, Zeng et al. (2019), using methods of indoor cultivating of soybean seedlings and experiments, disclosed that a large amount of CAT transcription and significant enhancement of enzyme activity were observed under high aluminum stress. Researches have shown that the antioxidant enzyme activities in leaves of Pyracantha fortuneana and Rosa cymosa are significantly enhanced under severe drought stress, indicating the strong resistance to drought stress of these species, however the antioxidant enzyme activities are greatly weakened in leaves of Broussonetia papyrifera and Cinnamomum bodinieri under same conditions, indicating the weaker resistance to drought stress (Liu et al., 2011). Here, our experiment showed that CAT and POD activities in barley seedlings significantly weakened under non-freeze-thaw stress. The results suggested a possible reason of lipid peroxidation on the cell membrane affected by stresses duration, leading to the damage to cells and the effect on the synthesis of substances like proteins in cells, at last reducing the antioxidant enzyme activity. This is consistent with the study by Gao et al. (2012). Moreover, an observed decrease in SOD activity in the leaves of Camptotheca acuminata seedlings accompanied low temperature stress, which was found by Feng et al. (2002). It was worth noting that CAT and POD activities increased, while SOD activity decreased with a decrease of temperature, which could be explained by the role played by SOD as the first line in defensing and eliminating reactive oxygen species (ROS). A large consumption of SOD in the process of eliminating ROS and an inefficient synthesis of enzymes in the case of low temperature were confirmed in the research results of Bao et al. (2019). 
Environmental stress can disrupt the homeostasis of cells and the dynamic balance between production and clearance of ROS, leading to excessive accumulation of ROS in cells, causing the oxidative damage to biomolecules such as lipids (Mano, 2012), proteins (Dean et al., 1997) and nucleic acids (Cadet et al., 2003), and the disruption of osmotic balance in plants (Bian et al., 2018), which were discussed in detail in numerous studies. MDA is the end product of lipid peroxidation and can be induced by stress in plants organ, e.g. leaves, shoots or roots (Iseri et al., 2013; Karagoz et al., 2018). In this paper, MDA content in barley seedlings increased under the single or combined stress of salinity and drought, importantly, MDA content accumulated more under single salinity stress than that under combined stress. In addition to osmotic stress on seedlings, salinity stress, compared with drought, is accompanied by high $\mathrm{pH}$ stress as well, causing damage to plant cell membranes and eventually leading to the accumulation of MDA, which has been confirmed in a study by Ali et al. (2011). The freeze-thaw manipulation treatments decreased the MDA content of barley seedlings, during which, the activities-enhanced CAT played a key regulatory role (Wu et al., 2018).

\section{Conclusion}

In summary, as an important crop on the Qinghai-Tibet Plateau, barley has equipped with great resistance to the freeze-thaw environment within the long-term evolution. Considering current global warming, soil salinization and drought have become increasingly serious, resulting in physiological responses like the accumulation of MDA and the changes in antioxidant enzymes activity. Herein we showed that either single or compound stresses of drought, salinity and freeze-thaw could make MDA accumulated excessively in seedlings because of the imbalance between oxygen free radical reaction and lipid peroxidation reaction, which caused oxidative stress on plants, affecting the stability of plant cells. Moreover, the contents of MDA and SP in barley seedlings increased significantly under the combined stresses of salinity and drought, while the RWC significantly reduced. As a conclusion, to avoid simultaneous occurrence of drought and salinity stress, the intensity of spring irrigation is supposed to increase in areas with severe drought stress. Though the resistance characteristics of plants under one freeze-thaw cycle were studied in this paper, in view of multiple freeze-thaw cycles in nature, one important future direction of physiological responses to freeze-thaw stress is studying the different resistance characteristics of plant between under one freeze-thaw cycle and under multiple freeze-thaw cycles.

Acknowledgments. This work was sponsored by the National Natural Science Foundation of China (Grant Nos. 31772669 and 32071874) and the 111 Project (B16020). The funding bodies were not involved in the design of the study, collection, analysis, and interpretation of data, and in writing the manuscript.

\section{REFERENCES}

[1] Ahmed, I. M., Nadira, U. A., Bibi, N., Cao, F., He, X., Zhang, G., Wu, F. (2015): Secondary metabolism and antioxidants are involved in the tolerance to drought and salinity, separately and combined, in Tibetan wild barley. - Environmental and Experimental Botany 111: 1-12. 
[2] Ahsan, N., Lee, D. G., Lee, S. H., Kang, K. Y., Lee, J. J., Kim, P. J., Yoon, H. S., Kim, J. S., Lee, B. H. (2007): Excess copper induced physiological and proteomic changes in germinating rice seeds. - Chemosphere 67: 1182-1193.

[3] Alexander, R. D., Wendelboe-Nelson, C., Morris, P. C. (2019): The barley transcription factor HvMYB1 is a positive regulator of drought tolerance. - Plant Physiology and Biochemistry 142: 246-253.

[4] Ali, S., Bai, P., Zeng, F., Cai, S., Shamsi, H. I., Qiu, B., Wu, F., Zhang, G. (2011): The ecotoxicological and interactive effects of chromium and aluminum on growth, oxidative damage and antioxidant enzymes on two barley genotypes differing in Al tolerance. Environmental and Experimental Botany 70: 185-191.

[5] Alvarez-Acosta, C., Marrero-Dominguez, A., Gallo-Llobet, L., Gonzalez-Rodriguez, A. M. (2019): Effects of $\mathrm{NaCl}$ and $\mathrm{NaHCO} 3$ stress on morphological growth and nutrient metabolism on selected avocados (Persea americana Mill.). - Journal of Plant Nutrition 42: 164-177.

[6] Arfan, M., Zhang, C., Zhang, D. W., Li, D. X., Yan, J. J., You, M. H., Bai, S. Q., Lin, H. $\mathrm{H}$. (2019): $\mathrm{CO}_{2}$-exchange and chlorophyll fluorescence responses of forage grasses during salt stress and recovery in Qinghai-Tibetan Plateau (QTP). - Pakistan Journal of Botany 51: 1615-1628.

[7] Bae, H., Kim, M. S., Sicher, R. C., Bae, H. J., Bailey, B. A. (2006): Necrosis- and ethyleneinducing peptide from Fusarium oxysporum induces a complex cascade of transcripts associated with signal transduction and cell death in arabidopsis. - Plant Physiology 141: 1056-1067.

[8] Bao, G., Ao, Q., Li, Q., Bao, Y., Zheng, Y., Feng, X., Ding, X. (2017): Physiological Characteristics of Medicago sativa L. in Response to Acid Deposition and Freeze-Thaw Stress. - Water Air and Soil Pollution 228: 376.

[9] Bao, G., Zhang, M. Y., Li, Y. F., Chang, Y. X., Tang, W. Y., Zhu, S. N., Fan, C. X., Ding, X. M. (2019): Physiological responses of alfalfa seedlings to freeze-thaw cycles and alkaline salt stress. - Fresenius Environmental Bulletin 28: 4114-4122.

[10] Bian, W. J., Bao, G. Z., Qian, H. M., Song, Z. W., Qi, Z. M., Zhang, M. Y., Chen, W. W., Dong, W. Y. (2018): Physiological Response Characteristics in Medicago sativa Under Freeze-Thaw and Deicing Salt Stress. - Water Air and Soil Pollution 229: 196.

[11] Bibi, S., Wang, L., Li, X., Zhang, X., Chen, D. (2019): Response of Groundwater Storage and Recharge in the Qaidam Basin (Tibetan Plateau) to Climate Variations from 2002 to 2016. - Journal of Geophysical Research-Atmospheres 124: 9918-9934.

[12] Cadet, J., Douki, T., Gasparutto, D., Ravanat, J. L. (2003): Oxidative damage to DNA: formation, measurement and biochemical features. - Mutation Research-Fundamental and Molecular Mechanisms of Mutagenesis 531: 5-23.

[13] Colom, M. R., Vazzana, C. (2001): Drought stress effects on three cultivars of Eragrostis curvula: photosynthesis and water relations. - Plant Growth Regulation 34: 195-202.

[14] Dean, R. T., Fu, S., Stocker, R., Davies, M. J. (1997): Biochemistry and pathology of radical-mediated protein oxidation. - The Biochemical journal 324(Pt 1): 1-18.

[15] Duan, B., Yang, Y., Lu, Y., Korpelainen, H., Berninger, F., Li, C. (2007): Interactions between water deficit, ABA, and provenances in Picea asperata. - Journal of Experimental Botany 58: 3025-3036.

[16] Feng, J., Zhang, Y., Yang, T. (2002): Effect of Low Temperature Stress on the Membranelipid Peroxidation and the Concentration of Free Proline in Camptotheca acuminata Seedling. - Forest Research 15: 197-202.

[17] Gao, Y., Zhu, Y., Yang, Z., Du, H. (2012): Effects of Drought Stress and Recovery on Antioxidant Enzyme Activities of Agropyron cristatum. - Acta Agrestia Sinica 20: 6.

[18] Gong, Z., Chen, W., Bao, G., Sun, J., Ding, X., Fan, C. (2020): Physiological response of Secale cereale L. seedlings under freezing-thawing and alkaline salt stress. Environmental science and pollution research 27: 1499-1507. 
[19] Guo, H., Hu, T., Fu, J. (2012): Effects of saline sodic stress on growth and physiological responses of Lolium perenne. - Acta Prataculturae Sinica 21: 8.

[20] Hao, W., Arora, R., Yadav, A. K., Joshee, N. (2009): Freezing Tolerance and Cold Acclimation in Guava (Psidium guajava L.). - Hortscience 44: 1258-1266.

[21] Hazman, M., Hause, B., Eiche, E., Riemann, M., Nick, P. (2016): Different forms of osmotic stress evoke qualitatively different responses in rice. - Journal of Plant Physiology 202: 45-56.

[22] He, X., Zeng, J., Cao, F., Ahmed, I. M., Zhang, G., Vincze, E., Wu, F. (2015): HvEXPB7, a novel beta-expansin gene revealed by the root hair transcriptome of Tibetan wild barley, improves root hair growth under drought stress. - Journal of Experimental Botany 66: 7405-7419.

[23] Hou, X. Q., Hou, G. L., Wang, F. F., Wang, Q. B. (2018): Precipitation change and its effects on prehistorical human activities in the Gonghe Basin, Northeastern Qinghai-Tibet Plateau during middle and late Holocene. - IOP Conf. Ser.: Earth Environ. Sci. 121032016.

[24] Iseri, O. D., Korpe, D. A., Sahin, F. I., Haberal, M. (2013): Hydrogen peroxide pretreatment of roots enhanced oxidative stress response of tomato under cold stress. - Acta Physiologiae Plantarum 35: 1905-1913.

[25] Karagoz, H., Cakmakci, R., Hosseinpour, A., Kodaz, S. (2018): Alleviation of water stress and promotion of the growth of sugar beet (Beta vulgaris L.) plants by multi-traits rhizobacteria. - Applied Ecology and Environmental Research 16: 6801-6813.

[26] Kong, X., Yi, X. (2008): Experimental techniques for plant physiology. $-1^{\text {st }}$ ed., Chinese Agricultural Press, Beijing.

[27] Lee, D. G., Ahsan, N., Lee, S. H., Lee, J. J., Bahk, J. D., Kang, K. Y., Lee, B. H. (2009): Chilling stress-induced proteomic changes in rice roots. - Journal of Plant Physiology 166: $1-11$.

[28] Liu, C., Liu, Y., Guo, K., Fan, D., Li, G., Zheng, Y., Yu, L., Yang, R. (2011): Effect of drought on pigments, osmotic adjustment and antioxidant enzymes in six woody plant species in karst habitats of southwestern China. - Environmental and Experimental Botany 71: 174-183.

[29] Liu, H., Able, A. J., Able, J. A. (2019): Genotypic performance of Australian durum under single and combined water-deficit and heat stress during reproduction. - Scientific Reports 9: 14986.

[30] Mano, J. (2012): Reactive carbonyl species: Their production from lipid peroxides, action in environmental stress, and the detoxification mechanism. - Plant Physiology and Biochemistry 59: 90-97.

[31] Shereen, A., Khanzada, M. A., Baloch, M. A. W., Asma, B. H., Shirazi, M. U., Khan, M. A., Arif, M. (2019): Effects of peg induced water stress on growth and physiological responses of rice genotypes at seedling stage. - Pakistan Journal of Botany 51: 2013-2021.

[32] Souza, R. P., Machado, E. C., Silva, J. A. B., Lagoa, A., Silveira, J. A. G. (2004): Photosynthetic gas exchange, chlorophyll fluorescence and some associated metabolic changes in cowpea (Vigna unguiculata) during water stress and recovery. - Environmental and Experimental Botany 51: 45-56.

[33] Wang, F., Guo, X., Zhang, F., Wang, Y., Yu, A., Zhang, J., Fonti, P., Liu, J. (2019): Variations in leaf traits of Juniperus przewalskii from an extremely arid and cold environment - Science of the Total Environment 689: 434-443.

[34] Warner, R. (2007): Applied Statistics: From Bivariate Through Multivariate Techniques. $2^{\text {nd }}$ ed. SAGE Publications, Thousand Oaks, California.

[35] Wu, Y., Wu, J., Bai, T., Liu, Z., Zheng, D. (2018): Physiological response and cold resistance of C. japonica'Naidong'and C. japonica var. decumbens under different low temperature stress. - Journal of Henan Agricultural University 52: 9.

[36] Xu, H. P., Zhang, J., Pang, X. P., Wang, Q., Zhang, W. N., Wang, J., Guo, Z. G. (2019): Responses of plant productivity and soil nutrient concentrations to different alpine grassland degradation levels. - Environmental Monitoring and Assessment 191: 678. 
[37] Yin, C. Y., Duan, B. L., Wang, X., Li, C. Y. (2004): Morphological and physiological responses of two contrasting Poplar species to drought stress and exogenous abscisic acid application. - Plant Science 167: 1091-1097.

[38] Zeng, C. Q., Liu, W. X., Hao, J. Y., Fan, D. N., Chen, L. M., Xu, H. N., Li, K. Z. (2019): Measuring the expression and activity of the CAT enzyme to determine $\mathrm{Al}$ resistance in soybean. - Plant Physiology and Biochemistry 144: 254-263.

[39] Zhang, Y., Xu, G., Li, P., Li, Z., Wang, Y., Wang, B., Jia, L., Cheng, Y., Zhang, J., Zhuang, S., Chen, Y. (2019): Vegetation Change and Its Relationship with Climate Factors and Elevation on the Tibetan Plateau. - International journal of Environmental Research and Public Health 16(23): 4709. 